\title{
Broadband over Power Line
}

\author{
Seema $^{1}$, Dr. Neetu Sharma ${ }^{2}$ \\ ${ }^{1}$ Student of M. Tech, \\ ${ }^{2} \mathrm{HOD}(\mathrm{CSE}$ Department)
}

\begin{abstract}
In this paper various aspects of Broadband over Power line (BPL) in Communication Network have been presented. Broadband access and services are delivered using a variety of technologies, network architectures and transmission methods. The objective of this paper is to highlight the BPL access technology in term of features, working, drawbacks, deployment \& future challenges, advantages and scope etc. BPL is now a growing communication network technology which is quite fast hitting the competitive market of broad band internet services in international telecom environment. Even in the absence of these regulatory measures, BPL is gaining ground in these Countries despite strong protests from those agencies which are vulnerable to interference because of BPL.
\end{abstract}

Keywords: Broadband, Internet Access, Power-line, Power-Line Communications, Communication Network, Othogonal Frequency Division Multiplexing (OFDM).

\section{Introduction}

BPL provides high speed internet access to eliminate the need of transmission of data over copper cables. BPL technology uses the combination of wireless networking and modems etc. it uses power grid infrastructure to provide high speed internet access. It is totally based on power line communication. BPL must achieve to gain widespread acceptance as a competitive broadband access technology. This is accomplished by using a number of devices to place the signal onto the wire, ensure it is transported with enough strength and integrity, and finally to receive and process the signal.

\section{BPL Types}

It is of two types in house BPL and access BPL.

In house BPL we use formal classification because of their low emission present minimum risk of interference.it work on low voltage electricity. In-house BPL systems directly compete with the coaxial cable, phone line, and wireless solutions. In-house BPL was once preferred over the phone and cable line systems because all areas of a household are wired for electric, whereas only certain locations in the house have phone and cable outlets. The transmission standards for In-house BPL were developed by the HomePlug Power line Alliance. The HomePlug physical layer standards use Orthogonal Frequency Division Multiplexing (OFDM)7 much like the DSL standards, but usea burst mode rather than a continuous mode.

\begin{tabular}{|c|c|c|c|}
\hline & OFDM & $\begin{array}{c}\text { Spread } \\
\text { Spectrum } \\
\text { Techniques (FH } \\
\text { and DS) }\end{array}$ & Single Carrier \\
\hline $\begin{array}{c}\text { Spectral } \\
\text { Efficiency }\end{array}$ & Good & Poor & Moderate \\
\hline $\begin{array}{c}\text { Robustness } \\
\text { Against Channel } \\
\text { Distortions }\end{array}$ & Excellent & Not Good & Good \\
\hline $\begin{array}{c}\text { Robustness } \\
\text { Against } \\
\text { Impulsive Noise }\end{array}$ & Fair & Fair & Good \\
\hline $\begin{array}{c}\text { Ability to adapt } \\
\text { to channel } \\
\text { changes }\end{array}$ & Excellent & Fair & Good \\
\hline $\begin{array}{c}\text { EMC Aspects } \\
\text { Emplementation } \\
\text { Costs } \\
\text { (Equalizers, } \\
\text { etc.) }\end{array}$ & Good & Good-Excellent & Poor \\
\hline $\begin{array}{c}\text { Impair } \\
\text { Fingulizers }\end{array}$ & Poor & Poor (Equalizequired) \\
\hline
\end{tabular}

Figure 1: OFDM Feature Comparison

Access BPL is used on greater distance over much power. It process high potential for interference. Due to its greater potential to enter the broadband service market, this study will focus primarily on Access BPL, rather than In-house BPL. For the simplicity of this paper, I will be referring to Access BPL systems simply as BPL. Any further references to BPL will imply Access BPL unless specifically stated as In-house BPL. Thesesignals are capable of being carried throughout the utility power distribution grid. 


\section{International Journal of Science and Research (IJSR) \\ ISSN (Online): 2319-7064}

Index Copernicus Value (2013): 6.14 | Impact Factor (2015): 6.391

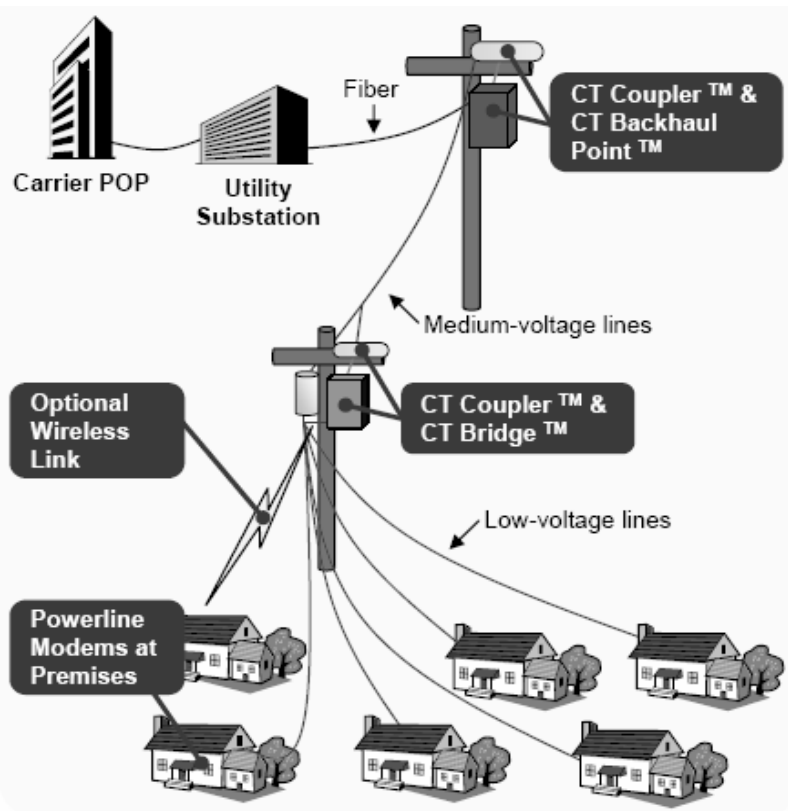

The important characteristic of OFDM is its ability to spread the data signals over a much greater bandwidth allowing it to adaptively overcome noise in the communication system. The use of OFDM is also considered a critical feature allowing BPL to avoid certain frequencies.

\section{Kind of available Broadband Access Technologies}

Electric companies have deployed technologies such as SCADA (Supervisory Control and Data Acquisition) over powerlines to perform simple command/control functions at remote locations, such as sub-stations, using the electric transmissions lines as the medium. Modulation techniques vary for traditional PLC, from FM to Wideband. While the technology appears promising, there are a number of issues with respect to its operation as well as the possibility of it interfering into radio services in other frequencies range.

Figure 2: BPL Power Line Bridge

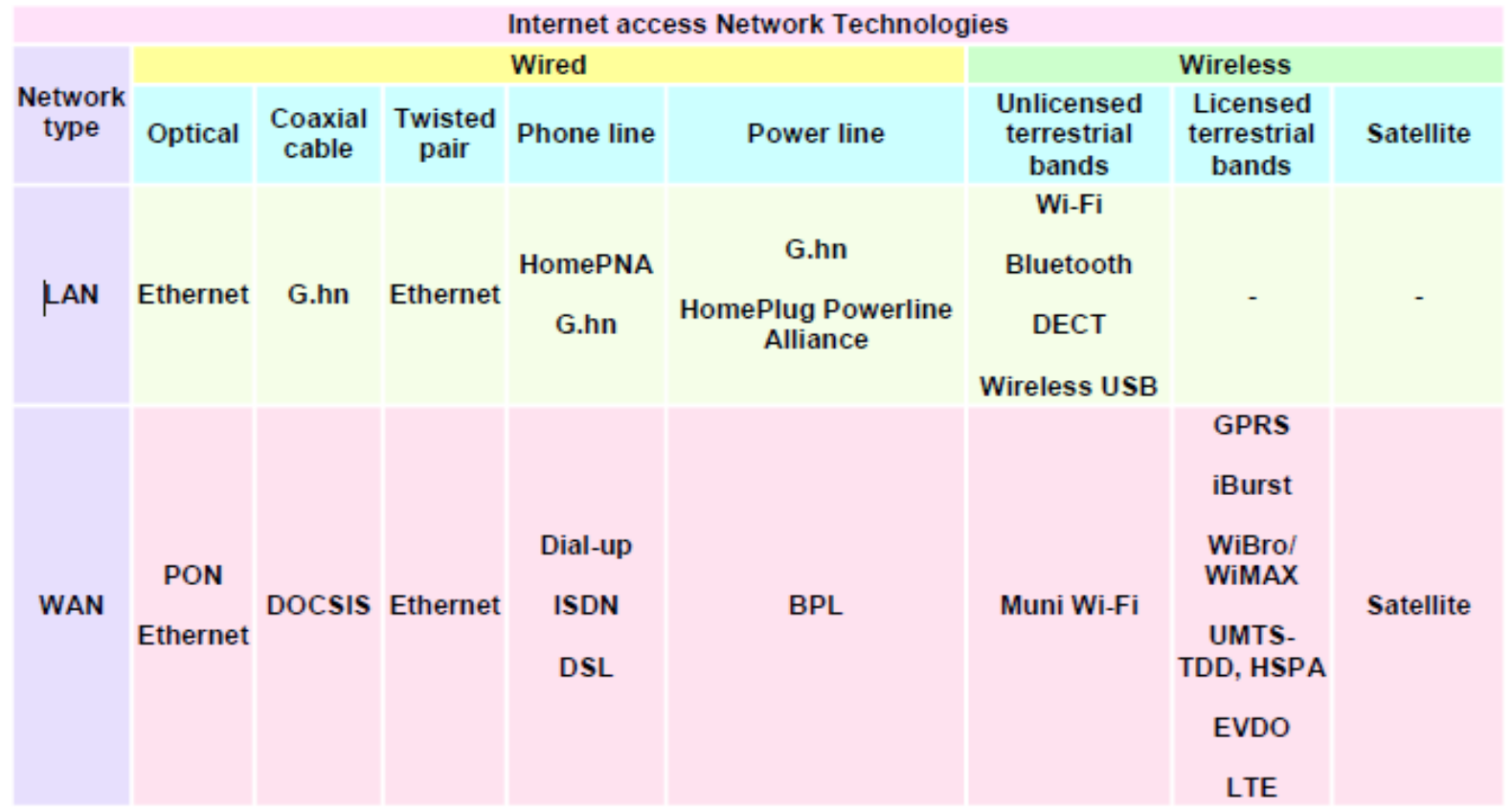

Figure 3: Internet Access Network Technology

\section{Current Status of BPL in the World}

A number of foreign governments includingUSA, Australia, Austria, China, Finland, Hong Kong, Hungary, Ireland, Italy, Korea, Japan, Netherlands, Poland, and Switzerland are currently studying BPL technology or have permitted equipment trials.

\section{BPL Architecture}

A computer (or any other device) would need only to plug a BPL "modem" into any outlet in an equipped building to have high speed internet access.

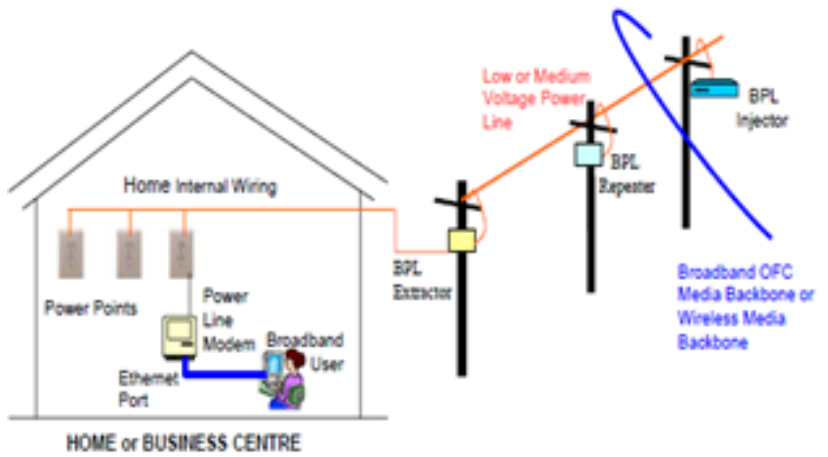

Figure 4: BPL General Architecture and Schematic

Advantages:

1) Wide Coverage

2) Cost

Volume 5 Issue 6, June 2016 www.ijsr.net 


\section{Disadvantages}

1) High noise source over power line.

2) Open circuit problem

3) Signal distortion and attenuation

4) Capacity

\section{Final Analysis}

Broadband over power lines presents a unique opportunity to provide universal broadband access using the existing power distribution grid. Despite a precarious start in the regulatory area, BPL has been able to largely overcome the issue of harmful interference. Although the optimal price setting methodology a regulated utility should employ when entering the competitive broadband services market remains uncertain, the utilities have found added incentives for the deployment of BPL in the efficiency improvements created in the power distribution grid. Although BPL may have a difficult time competing with cable and DSL in the established broadband services market on price alone, the performance enhancements provided by intelligent network capabilities will make tremendous headway towards defraying the cost of the infrastructure.

\section{Conclusion}

Even though the importance and direct socioeconomic impact of access to broadband services are wellunderstood, presently solely $4 \%$ of the Earth's population has access to some kind of broadband services, typically via DSL or cable modem. BPL offers a brand new, probably powerful different suggests that of providing high-speed net services, VoIP, and alternative broadband services to homes and businesses by exploitation existing MV and LV power lines. As a result of roughly $60 \%$ of Earth's inhabitants have access to power lines, BPL may play a major role in bridging the prevailing digital divide. The Broad Band over Power Line communication network technologies are new for Indian telecom network and will grow extensively in near future for higher capacity applications e.g. Triple Play services (telephony, data and TV etc.). Also BPL is a better option with less cost for network operators. BPL is already on the scene with commercial products readily available. Green Energy technologies like Solar, Wind etc. may be used as Power Line solutions. Combination of BPL with FTTX, DSL, PON etc. may be economical solution for access networks in future.

\section{References}

[1] "Availability of Advanced Telecommunications Capability in the United States." A Fourth Report to Congress.

[2] "Broadband Internet Access in OECD Countries: A Comparative Analysis."

[3] "Broadband over Power Lines Part 1."

[4] Bush, President George W. American Association of Community Colleges Annual Convention.

[5] Bush, President George W. US Department of Commerce, 24 June 2004.

[6] Calzada,Joan. "Access by Capacity and Peak-Load Pricing,"
[7] Wikipedia 2011

URL: http://en.wikipedia.org/wiki/Power_line_communicatio $\mathrm{n}$

[8] Broadband over power line for Indian telecom networkby Ram Krishna, R. K. Siddhartha Naveen Kumar, G. L. Jogi

[9] Broadband over power :An overview - By ShamimZiaee and Xavier N. Fernando Senior member of IEEE Ryerson University, Toronto, ON

[10]Consultation Paper on Broadband over Power Line (BPL) Communication Systems-report By Canada industry -July 2005 